\title{
Preventive effect of Lactobacillus fermentum Lee on activated carbon-induced constipation in mice
}

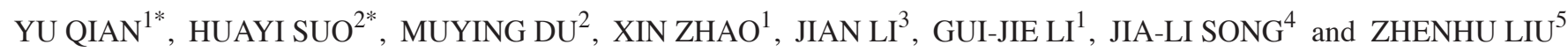 \\ ${ }^{1}$ Department of Biological and Chemical Engineering, Chongqing University of Education, Chongqing 400067; \\ ${ }^{2}$ College of Food Science, Southwest University, Chongqing 400715; ${ }^{3}$ Institute of Qinghai-Tibetan Plateau, \\ Southwest University for Nationalities, Chengdu, Sichuan 610041, P.R. China; ${ }^{4}$ Department of \\ Food Science and Nutrition, Pusan National University, Busan 609-735, Republic of Korea; \\ ${ }^{5}$ Xinjiang Academy of Agricultural Sciences, Urumqi, Xinjiang 830091, P.R. China
}

Received January 13, 2014; Accepted October 24, 2014

DOI: $10.3892 /$ etm.2014.2064

\begin{abstract}
The aim of this study was to investigate the effects of Lactobacillus fermentum Lee (LF-Lee) on activated carbon-induced constipation in ICR mice. ICR mice were orally administered lactic acid bacteria for nine days. Body weight, dietary and water intake, defecation status, gastrointestinal (GI) transit and defecation time, as well as levels of motilin (MTL), gastrin (Gas), endothelin (ET), somatostatin (SS), acetylcholinesterase (AChE), substance P (SP) and vasoactive intestinal peptide (VIP) in serum were measured to evaluate the preventive effects of LF-Lee on constipation. Bisacodyl, a laxative drug, was administered as a positive control. The time taken until the first defecation of a black stool for normal, control, bisacodyl- (100 mg/kg, oral administration), Lactobacillus bulgaricus (LB)-, LF-Lee low dose (L)- and LF-Lee high dose (H)-treated mice was 90, 218, 117, 180, 161 and $151 \mathrm{~min}$, respectively. Following the consumption of LB, LF-Lee (L) or LF-Lee $(\mathrm{H})$, or the oral administration of bisacodyl, the GI transit was reduced to $55.2,65.8,73.1$ and $94.6 \%$, respectively, of the transit in normal mice. The serum levels of MTL, Gas, ET, AChE, SP and VIP were significantly increased and those of SS were reduced in the mice treated with LF-Lee compared with those in the untreated control mice $(\mathrm{P}<0.05)$. These results demonstrate
\end{abstract}

Correspondence to: Professor Xin Zhao, Department of Biological and Chemical Engineering, Chongqing University of Education, 9 Xuefu Main Street, Nan'an, Chongqing 400067, P.R. China

E-mail: foods@live.cn

Professor Jian Li, Institute of Qinghai-Tibetan Plateau, Southwest University for Nationalities, Nansiduan, 16 Yihuan Road, Chengdu, Sichuan 610041, P.R. China

Email: lijian@swun.cn

${ }^{*}$ Contributed equally

Key words: Lactobacillus fermentum Lee, activated carbon, constipation, bisacodyl, gastrointestinal transit that lactic acid bacteria have preventive effects on constipation in mice and that LF-Lee has superior functional activity.

\section{Introduction}

Yak yogurt is a traditional dairy product from the Qinghai-Tibet Plateau. Rich in nutrients, it aids digestion, stimulates appetite and also has antibacterial, pore constringing, sedation and hypnosis effects. In addition, it can also be beneficial in patients with chronic mild diarrhea (1). Furthermore, it has also been found to reduce levels of cholesterol, prevent arteriosclerosis and cancer, and avoid premature aging (2). The authors of the present study have separated microorganisms from yak yoghurt prepared by Tibetan inhabitants and identified lactic acid bacteria, which have been named Lactobacillus fermentum Lee (LF-Lee).

Constipation is a common clinical condition that involves a reduction in the frequency of defecation, the quantity of feces, dry stools and defecation difficulties. When activated carbon is administered to mice, constipation occurs due to a reduction in the quantity of gastrointestinal (GI) fluid and weakening of GI peristalsis as the activated carbon is absorbed on the surface of the GI mucosa, which reduces GI functioning. Therefore, numerous studies have carried out experiments on animal models with activated carbon-induced constipation (3). Previous studies have used the activated carbon-induced constipation model to demonstrate the effectiveness of drugs for constipation treatment $(4,5)$. In addition, one study revealed that a megadose of activated carbon resulted in digestive tract obstruction (6).

In the present study, the functional effects of LF-Lee in the alimentary tract were examined using an activated carbon-induced mouse model of constipation. The GI transit, time taken until the first defecation of a black stool, and serum assays of levels of motilin (MTL), gastrin (Gas), endothelin (ET), somatostatin (SS), acetylcholinesterase (AChE), substance P (SP) and vasoactive intestinal peptide (VIP) were examined. Bisacodyl was used as a positive control. Bisacodyl is a drug routinely used in the treatment of acute and chronic constipation. It works by stimulating the rectal nerve endings to promote bowel motility. The laxity helps to treat constipation (7-9). 
With LF-Lee as the subject, the present study took Lactobacillus bulgaricus (LB), which is used in yoghurt production, as a comparative strain. By comparing the bile tolerance and hydrophobic properties of LF-Lee and LB, the ability of LF-Lee to pass through the stomach and guts and adhere to the small intestine was studied. This allowed further study of its curative effect to constipation, thus laying a scientific foundation for the development of lactic acid bacteria.

\section{Materials and methods}

Microorganism strains. LF-Lee was separated and identified from yak yoghurt produced in the Hongyuan Grassland (Ngawa Prefecture, China) and deposited at the China Center for Type Culture Collection (CCTCC, Wuhan, China), bearing CCTCC Accession Number M2013512. LB was purchased from the Institute of Microbiology of the Chinese Academy of Sciences (Beijing, China).

Animals. Seven-week-old female ICR mice $(n=120)$ were purchased from the Experimental Animal Center of Chongqing Medical University (Chongqing, China). The mice were maintained in a temperature- and humidity-controlled (temperature $25 \pm 2^{\circ} \mathrm{C}$, relative humidity $50 \pm 5 \%$ ) facility with a 12-h light/dark cycle and free access to a standard rat chow diet and water. The present study was approved by the Ethics Committee of ChongQing Medical University.

Endurance capacity of lactic acid bacteria to artificial gastric juice of $\mathrm{pH}$ 3.0. Artificial gastric juice was prepared using $0.2 \% \mathrm{NaCl}$ and $0.35 \%$ pepsin, adjusted to $\mathrm{pH} 3.0$ and then vacuum-filtered to remove bacteria on a clean bench. A total of $5 \mathrm{ml}$ reactivated bacterial culture was centrifuged at $1,006 \mathrm{x} \mathrm{g}$ for $10 \mathrm{~min}$. The bacterial pellet was collected and re-suspended in $5 \mathrm{ml}$ sterile saline, following which $1 \mathrm{ml}$ suspension was mixed with $9 \mathrm{ml}$ artificial gastric juice and incubated in a thermostatic oscillator at $37^{\circ} \mathrm{C}$ and $300 \mathrm{rpm}$. Subsequently, $200 \mu 1$ sample was pipetted at 0 and $3 \mathrm{~h}$, poured onto a plate with de Man, Rogosa and Sharpe (MRS) agar and then incubated at $37^{\circ} \mathrm{C}$ for $48 \mathrm{~h}$. The number of colony-forming units (CFUs) was counted and the survival rate was determined, as previously described (10).

Determination of the bacterial tolerance to bile salt (ox gall) of different concentrations. A total of $100 \mu \mathrm{l}$ reactivated bacterial culture was inoculated at $2 \%(\mathrm{v} / \mathrm{v})$ into MRS-thio (MRS $+0.2 \%$ sodium thioglycolate) broth which contained 0.0 (control), 0.3, 0.5 and 1.0\% ox gall (Shanghai Ekear Bio\&Tech Co., Ltd., Shanghai, China), respectively. Following incubation at $37^{\circ} \mathrm{C}$ for $24 \mathrm{~h}$, the optical density (OD) value of each culture was measured and the tolerance of the bacterial strain to ox gall was determined by comparing the OD of the ox gall tube with that of the control tube (10).

Determination of the hydrophobic properties of lactic acid bacteria. Reactivated bacterial culture $(5 \mathrm{ml})$ was centrifuged at $1,370 \mathrm{xg}$ for $10 \mathrm{~min}$. The bacterial pellet was collected, resuspended in $5 \mathrm{ml}$ phosphate-buffered saline (PBS; $50 \mathrm{mM}$; $\mathrm{pH}$ 6.5) and centrifuged at $1,370 \times \mathrm{g}$ for $10 \mathrm{~min}$; the process was then repeated. Using PBS as a blank for absorption, the final bacterial suspension was adjusted using PBS to produce a
1.00 absorbance $\left(\mathrm{A}_{0}\right)$ at $560 \mathrm{~nm}$. A total of $4 \mathrm{ml}$ of the adjusted bacteria suspension was added to $0.8 \mathrm{ml}$ dimethylbenzene, vibrated for $30 \mathrm{sec}$ and allowed to settle into layers. The aqueous layer was measured for absorbance (A) at $560 \mathrm{~nm}$ (blank: PBS) and the results were recorded (11).

Induction of constipation in mice. To investigate the preventive effects of LF-Lee against activated carbon-induced constipation, the animals were divided into six groups with 20 mice in each group. The experimental design was as follows: the normal and control groups received a normal diet for nine days; the LF-Lee high dose (H), LF-Lee low dose (L) and LB groups were orally administered a $2-\mathrm{ml}$ dose of concentration $1 \times 10^{9}$, $1 \times 10^{8}$ and $1 \times 10^{9} \mathrm{CFU} / \mathrm{ml}$, respectively; the drug cure group mice were treated with a $100 \mathrm{mg} / \mathrm{kg}$ dose of bisacodyl dissolved in water for nine days. The control and treatment groups received an oral administration of activated carbon $(0.2 \mathrm{ml} 10 \%$ activated carbon, w/w; activated carbon dissolved in $10 \%$ gum arabic) at 18:00 from the sixth to the ninth day to induce constipation (12). The body weight, dietary and water intake, and stool weight and moisture were measured at 09:00 every day.

Measurement of the defecation status of the mice. This measurement was performed to determine whether the prokinetic actions of the lactic acid bacteria were capable of propagating a prokinetic signal along the entire length of the GI tract. The excreted fecal pellets of individual mice were collected daily at 09:00 for the duration of the experiment. The total number, weight and water content of the pellets were determined. The water content was calculated as the difference between the wet and dry weight of the pellet. After $16 \mathrm{~h}$, the mice in the control and treatment groups received $10 \%$ activated carbon and the normal group was administered $10 \%$ gum arabic by intragastric gavage. The animals were individually placed into small transparent cages and allowed unrestricted access to food and tap water. The length of time from carbon meal administration to the appearance of darkened feces was recorded. Feces were collected, counted, evaluated for water content and weighed following the intragastric gavage administration.

GI transit and defecation time. Mice were fasted for $16 \mathrm{~h}$ from the ninth day at 18:00; however, they were not deprived of water. After $16 \mathrm{~h}$, the mice in the control and treatment groups received an oral administration of $10 \%$ activated carbon while the mice in the normal group received an oral administration of $10 \%$ gum arabic. After $30 \mathrm{~min}$, the mice were sacrificed by cervical dislocation under anesthesia with diethyl ether. A total of 10 mice in each group were dissected and the small intestine, from the pylorus to the cecum, was carefully removed. The GI transit of each mouse was calculated as the percentage of the distance traveled by the activated carbon meal relative to the total length of the small intestine. The following equation was used to calculate GI transit: GI transit $(\%)=$ distance traveled by the activated carbon/total length of the small intestine $\mathrm{x} 100$. The remaining 10 mice from each group were used to measure the time taken to the first defecation of a black stool following oral administration of $10 \%$ activated carbon.

Levels of MTL, Gas, ET, SS, AChE, SP and VIP in the serum. The levels of MTL, Gas, ET, SS, AChE, SP and VIP in the 
Table I. Resistance to biological barriers and the level of hydrophobicity of Lactobacillus fermentum Lee (LF-Lee).

\begin{tabular}{lccrrr} 
& & & \multicolumn{3}{c}{ Growth in bile salt (\%) } \\
\cline { 4 - 6 } Strain & $\begin{array}{c}\text { Survival in artificial } \\
\text { gastric juice of pH 3.0 }(\%)\end{array}$ & Hydrophobic property (\%) & $0.3 \%$ & $0.5 \%$ & $1.0 \%$ \\
\hline LF-Lee & $87.99 \pm 5.21$ & $68.20 \pm 3.72$ & $25.31 \pm 2.03$ & $20.17 \pm 1.89$ & $15.22 \pm 1.14$ \\
LB & $27.81 \pm 3.41$ & $25.56 \pm 2.71$ & $2.61 \pm 0.34$ & $1.57 \pm 0.37$ & $1.31 \pm 0.22$ \\
\hline
\end{tabular}

Values presented are the mean \pm standard deviation. LB, Lactobacillus bulgaricus.

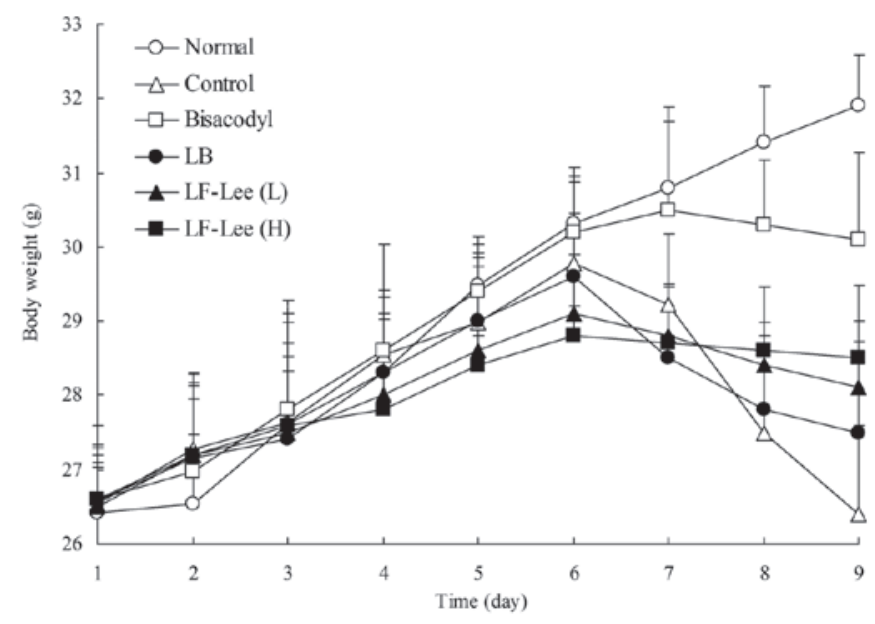

Figure 1. Body weights of mice during the experiment ( $\mathrm{n}=10$ per group). The dose of bisacodyl was $100 \mathrm{mg} / \mathrm{kg}$ body weight (bw). LB, Lactobacillus bulgaricus $\left[1.0 \times 10^{9}\right.$ colony-forming unit (CFU)/kg bw]; LF-Lee (L), Lactobacillus fermentum Lee low dose $\left(0.5 \times 10^{9} \mathrm{CFU} / \mathrm{kg}\right.$ bw); LF-Lee $(\mathrm{H})$, Lactobacillus fermentum Lee high dose (1.0x $\left.10^{9} \mathrm{CFU} / \mathrm{kg} \mathrm{bw}\right)$.

serum were determined using radioimmunoassay kits (Beijing Puer Weiye Biotechnology Co., Ltd., Beijing, China). The serum was collected from the heart following surgery.

Statistical analysis. Data are presented as mean \pm standard deviation. Differences between the mean values for individual groups were assessed using a one-way analysis of variance (ANOVA) with Duncan's multiple range test. $\mathrm{P}<0.05$ was considered to indicate a statistically significant difference. SAS 9.1 (SAS Institute Inc., Cary, NC, USA) was used to carry out the statistical analyses.

\section{Results}

Biological barrier resistance and hydrophobic properties of lactic acid bacteria. The GI survival abilities of the lactic acid bacteria were evaluated using synthetic gastric juice, bile salt and hydrophobic property tests. LF-Lee revealed higher GI survival abilities than LB (Table I). In particular, in the different concentrations of bile salt, the growth of LF-Lee was 10-12-fold higher than that of LB.

Body weight during the experiment. Body weight is an important marker of constipation in mice; the body weights of mice with activated carbon-induced constipation are lower compared with those of normal mice (12). Bisacodyl is an effective medicine for constipation treatment and it was used as a positive control in the present study. The normal mice had a normal diet and their body weight increased during the experiment. The body weight of the control mice with activated carbon-induced constipation was significantly decreased after six days. As shown in Fig. 1, following the initiation of activated carbon-induced constipation, the body weights of the mice in the LF-Lee and LB groups were significantly lower compared with those in the normal and bisacodyl-treated groups; however, they were higher than in the activated carbon-induced constipation control mice. LF-Lee treatment of the mice was able to alleviate the weight loss more effectively than LB treatment.

Effect of lactic acid bacteria on diet and water uptake. The dietary intake of the mice in each group remained stable from the first to the sixth day of the experiment. From the sixth day following the induction of constipation, the dietary intake of the control and treatment group mice decreased significantly; in particular, the intake of the control group decreased the most. However, the dietary intake of the LF-Lee groups remained higher than that of the LB and control groups, and approached that of the bisacodyl-treated group (Table II). The pattern of the uptake of drinking water by the mice in each group (Table III) was similar to that of the dietary intake. Thus, in the present study, LF-Lee was able to reduce dietary intake loss and thereby relieve anorexia following the induction of constipation.

Effect of lactic acid bacteria on the defecation status of mice. Constipation refers to bowel movements that are infrequent or hard to pass. Thus, pain in the abdomen and bloating are characteristics of constipation. There are a number of causes of constipation, including medication, poor bowel habits, a diet low in fiber, abuse of laxatives, hormonal disorders and disease that may be primarily of other parts of the body but that also affects the colon. Therefore, defecation is the most important criterion of constipation. The current study divided defecation status into three parts: i) defecation weight (g) which was observed as a main point to estimate the constipation situation; if the defecation weight was heavy, the mice had positive defecation qualities; ii) particle counts of defecation (pieces), where a greater number of pieces defecated implied that mice had good GI movement; iii) water content of defecation, where a higher water content indicated improved stool qualities. From the first to the sixth day, the defecation weight $(\mathrm{g})$, particle counts of defecation and water content of defecation (\%) in each group were not significantly different. However, the defecation weight and particle counts 
Table II. Food intake $(\mathrm{g})$ by the various groups of mice during the experiment.

\begin{tabular}{|c|c|c|c|c|c|c|}
\hline \multirow[b]{2}{*}{ Treatment } & \multirow[b]{2}{*}{ Normal } & \multirow[b]{2}{*}{ Control } & \multirow[b]{2}{*}{ Bisacodyl } & \multirow[b]{2}{*}{ LB } & \multicolumn{2}{|c|}{ LF-Lee (x109 CFU/kg bw) } \\
\hline & & & & & 0.5 & 1.0 \\
\hline Day 1 & $2.69 \pm 0.12$ & $2.66 \pm 0.17$ & $2.72 \pm 0.14$ & $2.74 \pm 0.12$ & $2.68 \pm 0.20$ & $2.72 \pm 0.12$ \\
\hline Day 2 & $2.73 \pm 0.13$ & $2.71 \pm 0.21$ & $2.77 \pm 0.12$ & $2.75 \pm 0.16$ & $2.70 \pm 0.18$ & $2.77 \pm 0.22$ \\
\hline Day 3 & $2.90 \pm 0.11$ & $2.84 \pm 0.20$ & $2.86 \pm 0.20$ & $2.79 \pm 0.14$ & $2.82 \pm 0.13$ & $2.90 \pm 0.15$ \\
\hline Day 4 & $3.04 \pm 0.15$ & $3.01 \pm 0.16$ & $3.02 \pm 0.15$ & $3.00 \pm 0.12$ & $3.01 \pm 0.21$ & $3.15 \pm 0.10$ \\
\hline Day 5 & $3.08 \pm 0.18$ & $3.06 \pm 0.15$ & $3.07 \pm 0.10$ & $3.12 \pm 0.11$ & $3.13 \pm 0.10$ & $3.17 \pm 0.12$ \\
\hline Day 6 & $3.10 \pm 0.16$ & $3.09 \pm 0.14$ & $3.12 \pm 0.11$ & $3.15 \pm 0.16$ & $3.15 \pm 0.10$ & $3.18 \pm 0.18$ \\
\hline Day 7 & $3.14 \pm 0.10$ & $2.60 \pm 0.22$ & $2.88 \pm 0.22$ & $2.63 \pm 0.12$ & $2.70 \pm 0.15$ & $2.77 \pm 0.12$ \\
\hline Day 8 & $3.15 \pm 0.13$ & $2.19 \pm 0.15$ & $2.78 \pm 0.17$ & $2.40 \pm 0.15$ & $2.53 \pm 0.11$ & $2.62 \pm 0.15$ \\
\hline Day 9 & $3.22 \pm 0.13$ & $2.02 \pm 0.09$ & $2.70 \pm 0.14$ & $2.22 \pm 0.13$ & $2.37 \pm 0.12$ & $2.42 \pm 0.11$ \\
\hline
\end{tabular}

Values presented are the mean \pm standard deviation ( $\mathrm{n}=10$ per group). LB, Lactobacillus bulgaricus; LF-Lee, Lactobacillus fermentum Lee; CFU, colony-forming unit; bw, body weight. The dose of bisacodyl was $100 \mathrm{mg} / \mathrm{kg}$ bw and the dose of LB was $1.0 \times 10^{9} \mathrm{CFU} / \mathrm{kg} \mathrm{bw}$.

Table III. Liquid uptake $(\mathrm{ml})$ by the various groups of mice during the experiment.

\begin{tabular}{|c|c|c|c|c|c|c|}
\hline \multirow[b]{2}{*}{ Treatment } & \multirow[b]{2}{*}{ Normal } & \multirow[b]{2}{*}{ Control } & \multirow[b]{2}{*}{ Bisacodyl } & \multirow[b]{2}{*}{ LB } & \multicolumn{2}{|c|}{ LF-Lee (x109 CFU/kg bw) } \\
\hline & & & & & 0.5 & 1.0 \\
\hline Day 1 & $6.24 \pm 0.20$ & $6.25 \pm 0.20$ & $6.24 \pm 0.20$ & $6.24 \pm 0.12$ & $6.25 \pm 0.20$ & $6.25 \pm 0.10$ \\
\hline Day 2 & $6.26 \pm 0.21$ & $6.28 \pm 0.15$ & $6.30 \pm 0.20$ & $6.22 \pm 0.16$ & $6.25 \pm 0.18$ & $6.27 \pm 0.17$ \\
\hline Day 3 & $6.27 \pm 0.12$ & $6.24 \pm 0.16$ & $6.30 \pm 0.16$ & $6.26 \pm 0.12$ & $6.27 \pm 0.15$ & $6.29 \pm 0.18$ \\
\hline Day 4 & $6.25 \pm .020$ & $6.25 \pm 0.20$ & $6.29 \pm 0.15$ & $6.28 \pm 0.16$ & $6.30 \pm 0.11$ & $6.28 \pm 0.13$ \\
\hline Day 5 & $6.32 \pm 0.20$ & $6.31 \pm 0.15$ & $6.32 \pm 0.20$ & $6.30 \pm 0.13$ & $6.30 \pm 0.22$ & $6.30 \pm 0.12$ \\
\hline Day 6 & $6.34 \pm 0.20$ & $6.28 \pm 0.21$ & $6.34 \pm 0.18$ & $6.32 \pm 0.10$ & $6.32 \pm 0.17$ & $6.31 \pm 0.16$ \\
\hline Day 7 & $6.37 \pm 0.21$ & $6.14 \pm 0.17$ & $6.28 \pm 0.15$ & $6.17 \pm 0.13$ & $6.22 \pm 0.15$ & $6.27 \pm 0.15$ \\
\hline Day 8 & $6.38 \pm 0.18$ & $5.75 \pm 0.18$ & $6.25 \pm 0.15$ & $5.93 \pm 0.14$ & $6.02 \pm 0.15$ & $6.10 \pm 0.10$ \\
\hline Day 9 & $6.40 \pm 0.22$ & $5.63 \pm 0.20$ & $6.21 \pm 0.17$ & $5.75 \pm 0.12$ & $5.93 \pm 0.15$ & $6.04 \pm 0.11$ \\
\hline
\end{tabular}

Values presented are the mean \pm standard deviation ( $\mathrm{n}=10$ per group). LB, Lactobacillus bulgaricus; LF-Lee, Lactobacillus fermentum Lee; $\mathrm{CFU}$, colony-forming unit; bw, body weight. The dose of bisacodyl was $100 \mathrm{mg} / \mathrm{kg}$ bw and the dose of LB was $1.0 \times 10^{9} \mathrm{CFU} / \mathrm{kg}$ bw.

of defecation in the bisacodyl-treated group were slightly higher compared with those in the other groups (Table IV). From the seventh to the ninth day, the defecation weight, particle counts of defecation and water content of defecation decreased to $0.37 \mathrm{~g}, 19$ pieces and $16 \%$, respectively, in the control group. Defecation weights and particle counts of defecation decreased to $0.74 \mathrm{~g} / 38$ pieces, $0.40 \mathrm{~g} / 21$ pieces, $0.55 \mathrm{~g} / 26$ pieces and $0.61 \mathrm{~g} / 30$ pieces, and water content of defecation to 40, 23, 27 and $34 \%$ in the bisacodyl, LB, LF-Lee (L) and LF-Lee $(\mathrm{H})$ groups, respectively. These results demonstrated that the LF-Lee groups had an improved defecation status compared with the control group following induced constipation and, thus, that LF-Lee may be used as a potential treatment for constipation.

Time taken to the first defecation of a black stool. The time taken to the first defecation of a black stool in each group of mice following the administration of activated carbon, is shown in Fig. 2. The defecation time was shortest (90 \pm 8 min) in the normal group and longest $(218 \pm 18 \mathrm{~min})$ in the control group. The defecation time in the bisacodyl-treated group $(117 \pm 6 \mathrm{~min})$ was higher compared with that in the normal group. The time taken to the first defecation of a black stool in the LB, LF-Lee (L) and LF-Lee (H) groups was $180 \pm 13$, $161 \pm 12$ and $151 \pm 9 \mathrm{~min}$, respectively. According to the results of the defecation times, LF-Lee revealed a stronger effect than LB as an inhibitor of constipation.

GI transit. The constipation-inhibiting effects of the treatments were determined by GI transit in mice following the administration of activated carbon $(0.2 \mathrm{ml} /$ mouse, $10 \%$ activated carbon). In the bisacodyl-treated group, the mean GI transit was $94.6 \pm 6.7 \%$, which was higher than that of the control group (42.1 $\pm 5.6 \%$; Fig. 3). The GI transits of the LB, LF-Lee (L) and LF-Lee $(\mathrm{H})$ groups were $55.2 \pm 4.6,65.8 \pm 4.1$ and $73.1 \pm 5.1 \%$, respectively. Thus, LF-Lee increased the GI transit compared 
Table IV. Defecation status of the various groups of mice during the experiment.

LF-Lee $\left(\mathrm{x} 10^{9} \mathrm{CFU} / \mathrm{kg}\right.$ bw)

\begin{tabular}{lcccccc}
\cline { 5 - 6 } Treatment & Normal & Control & Bisacodyl & LB & 0.5 & 1.0 \\
\hline Days 1-6 & & & & & & \\
$\quad$ Defecation weight (g) & $0.90 \pm 0.09$ & $0.94 \pm 0.11$ & $1.13 \pm 0.07$ & $0.91 \pm 0.05$ & $0.91 \pm 0.05$ & $0.89 \pm 0.06$ \\
Defecation particle counts (n) & $35 \pm 4$ & $36 \pm 7$ & $49 \pm 6$ & $36 \pm 2$ & $35 \pm 5$ & $36 \pm 4$ \\
Water content of defecation (\%) & $47 \pm 4$ & $47 \pm 5$ & $55 \pm 5$ & $49 \pm 4$ & $46 \pm 5$ & $48 \pm 4$ \\
Days 7-9 & & & & & & \\
Defecation weight (g) & $0.91 \pm 0.05$ & $0.37 \pm 0.06$ & $0.74 \pm 0.15$ & $0.40 \pm 0.05$ & $0.55 \pm 0.05$ & $0.61 \pm 0.05$ \\
Defecation particle counts (n) & $36 \pm 3$ & $19 \pm 6$ & $38 \pm 5$ & $21 \pm 3$ & $26 \pm 3$ & $30 \pm 5$ \\
Water content of defecation (\%) & $46 \pm 5$ & $16 \pm 3$ & $40 \pm 3$ & $23 \pm 2$ & $27 \pm 4$ & $34 \pm 6$ \\
\hline
\end{tabular}

${ }^{a}$ Treatment alone was administered; btreatment and activated carbon were administered. Values presented are the mean \pm standard deviation ( $\mathrm{n}=10$ per group). LB, Lactobacillus bulgaricus; LF-Lee, Lactobacillus fermentum Lee; CFU, colony-forming unit; bw, body weight. The dose of bisacodyl was $100 \mathrm{mg} / \mathrm{kg}$ bw and the dose of LB was $1.0 \times 10^{9} \mathrm{CFU} / \mathrm{kg}$ bw.

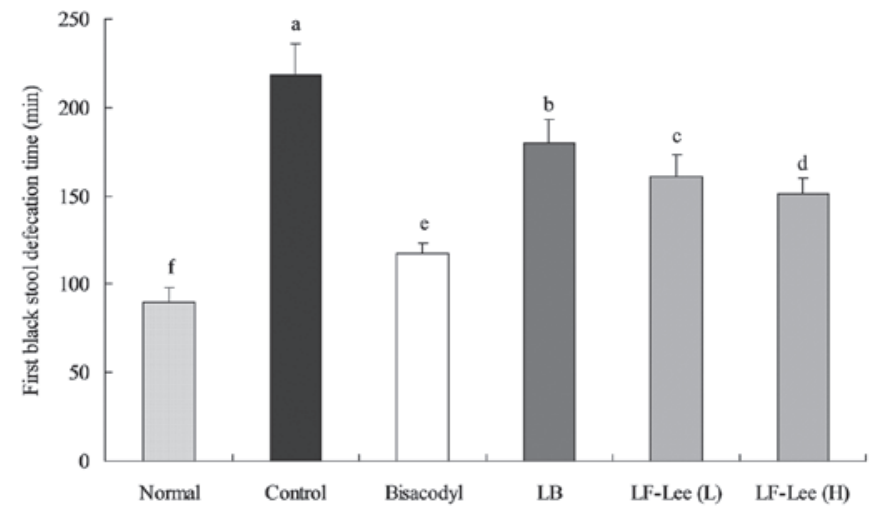

Figure 2. First black stool defecation time of mice in the various groups on the final day of the experiment, following the induction of constipation by activated carbon ( $\mathrm{n}=10$ per group). The dose of bisacodyl was $100 \mathrm{mg} / \mathrm{kg}$ body weight (bw). LB, Lactobacillus bulgaricus $\left[1.0 \times 10^{9}\right.$ colony-forming unit (CFU)/kg bw]; LF-Lee (L), Lactobacillus fermentum Lee low dose $\left(0.5 \times 10^{9} \mathrm{CFU} / \mathrm{kg}\right.$ bw); LF-Lee $(\mathrm{H})$, Lactobacillus fermentum Lee high dose $\left(1.0 \times 10^{9} \mathrm{CFU} / \mathrm{kg}\right.$ bw); ${ }^{\mathrm{a}-\mathrm{f}}$ Mean values with different letters over the bars are significantly different $(\mathrm{P}<0.05)$ according to Duncan's multiple range test.

with that of the control group and thereby reduced constipation and had an increased functional effect on GI transit.

Levels of MTL, Gas, ET, SS, AChE, SP and VIP in the serum. Normal mice demonstrated the highest levels of MTL, Gas, ET, AChE, SP and VIP among the groups; these levels were significantly reduced in the control mice $(\mathrm{P}<0.05$; Table $\mathrm{V})$. The levels of MTL, Gas, ET, AChE, SP and VIP in the bisacodyl-treated mice were similar to those of the normal mice. These levels in the lactic acid bacteria-treated mice approached those in the normal mice but were higher than those of the control mice. The LF-Lee-treated mice demonstrated higher levels of MTL, Gas, ET, AChE, SP and VIP compared with the LB-treated mice. Furthermore, the high dose LF-Lee-treated mice demonstrated similar levels of these substances to the normal and bisacodyl-treated mice. The levels of SS in mice showed the opposite tendency.

\section{Discussion}

Patients with constipation frequently present with anorexia (13). Therefore, dietary and water intake can be taken as standards to measure the severity of the constipation. Furthermore, patients with constipation also present with symptoms such as the weakening of intestinal peristalsis and difficulty in defecation $(14,15)$. When food is digested, the indigested content forms a stool. However, as intestinal peristalsis slows down, the rate of the digestive movement of the stool becomes slow. Once the movement of the stool slows down, more water is absorbed from the stool. The stool subsequently hardens and dries (16). Therefore defecation time, stool quantity and water content in the stool may all be used as standards to measure constipation.

Probiotics, including lactic acid bacteria, are usually present in food or are taken as oral supplements. They survive the strong acidic conditions in the stomach and upper intestinal tract and upon reaching their final destination (usually the large intestine), colonize and give play to their physiological efficacy (17). Therefore, in order to study whether probiotics are able to pass the through stomach and intestine to colonize the intestinal tract, external experiments to model the conditions in the intestinal tract were conducted. In these, the growth of lactic acid bacteria was analyzed in order to measure the endurance of the bacteria during a screening experiment. The potential probiotic function of bacteria may be identified by measuring their acid resistance, bile tolerance and hydrophobic properties (10). In the present study, LF-Lee revealed improved qualities of acid resistance, bile tolerance and hydrophobic properties compared with the common lactic acid bacteria, LB. These qualities indicate that the functional effects of LF-Lee may be suitable for humans.

The surviving bacteria passing through the stomach may contact bile acids, such as cholate, in the small intestine. The cholate tolerance of lactic acid bacteria is taken as a standard when identifying potential probiotics (18). In addition to being able to withstand cholate in the small intestine, lactic acid bacteria should be able to adhere to the mucous membrane of the small intestine. Therefore, the hydrophobic properties of lactic acid bacteria are taken as another standard (19). 
Table V. Effect of various treatments on serum levels in the mouse model of activated carbon-induced constipation (pg/ml).

\begin{tabular}{lcrrrrr}
\hline & & & & & LF-Lee (x10 CFU/kg bw) \\
\cline { 3 - 6 } Analyte & Normal & Control & Bisacodyl & LB & 0.5 & 1.0 \\
\hline MTL & $173.2 \pm 12.6^{\mathrm{a}}$ & $101.3 \pm 9.7^{\mathrm{f}}$ & $155.4 \pm 8.7^{\mathrm{b}}$ & $119.7 \pm .7 .7^{\mathrm{e}}$ & $134.2 \pm 7.6^{\mathrm{d}}$ & $143.7 \pm 8.1^{\mathrm{c}}$ \\
Gas & $80.2 \pm 3.2^{\mathrm{a}}$ & $44.3 \pm 2.7^{\mathrm{f}}$ & $73.6 \pm 2.6^{\mathrm{b}}$ & $50.2 \pm 2.1^{\mathrm{e}}$ & $59.2 \pm 2.2^{\mathrm{d}}$ & $67.2 \pm 2.8^{\mathrm{c}}$ \\
ET & $13.9 \pm 0.4^{\mathrm{a}}$ & $7.1 \pm 0.3^{\mathrm{f}}$ & $12.0 \pm 0.3^{\mathrm{b}}$ & $8.4 \pm 0.3^{\mathrm{e}}$ & $9.0 \pm 0.3^{\mathrm{d}}$ & $10.0 \pm 0.3^{\mathrm{c}}$ \\
SS & $33.2 \pm .1 .9^{\mathrm{f}}$ & $61.8 \pm 1.6^{\mathrm{a}}$ & $40.3 \pm 2.0^{\mathrm{e}}$ & $56.2 \pm 1.9^{\mathrm{b}}$ & $50.0 \pm 0.9^{\mathrm{c}}$ & $45.2 \pm 0.7^{\mathrm{d}}$ \\
AChE & $31.1 \pm 1.2^{\mathrm{a}}$ & $12.7 \pm 0.9^{\mathrm{f}}$ & $27.8 \pm 0.9^{\mathrm{b}}$ & $15.9 \pm 0.8^{\mathrm{e}}$ & $20.3 \pm 1.1^{\mathrm{d}}$ & $23.6 \pm 0.7^{\mathrm{c}}$ \\
SP & $63.2 \pm 2.8^{\mathrm{a}}$ & $37.2 \pm 1.9^{\mathrm{f}}$ & $55.3 \pm 1.7^{\mathrm{b}}$ & $41.3 \pm 0.5^{\mathrm{e}}$ & $45.7 \pm 0.6^{\mathrm{d}}$ & $50.3 \pm 0.8^{\mathrm{c}}$ \\
VIP & $52.3 \pm 1.9^{\mathrm{a}}$ & $30.6 \pm 1.0^{\mathrm{f}}$ & $47.1 \pm 1.1^{\mathrm{b}}$ & $33.6 \pm 0.9^{\mathrm{e}}$ & $38.8 \pm 1.0^{\mathrm{d}}$ & $42.7 \pm 0.6^{\mathrm{c}}$ \\
\hline
\end{tabular}

Values presented are the mean \pm standard deviation ( $\mathrm{n}=10$ per group). LB, Lactobacillus bulgaricus; LF-Lee, Lactobacillus fermentum Lee; CFU, colony-forming unit; bw, body weight; MTL, motilin; Gas, gastrin; ET, endothelin; SS, somatostatin; AChE, acetylcholinesterase; SP, substance P; VIP, vasoactive intestinal peptide. The dose of bisacodyl was $100 \mathrm{mg} / \mathrm{kg}$ bw and the dose of LB was $1.0 x 10^{9} \mathrm{CFU} / \mathrm{kg}$ bw. ${ }^{\mathrm{a}-\mathrm{f}} \mathrm{Mean}$ values with different letters in the same column are significantly different $(\mathrm{P}<0.05)$ according to Duncan's multiple range test.

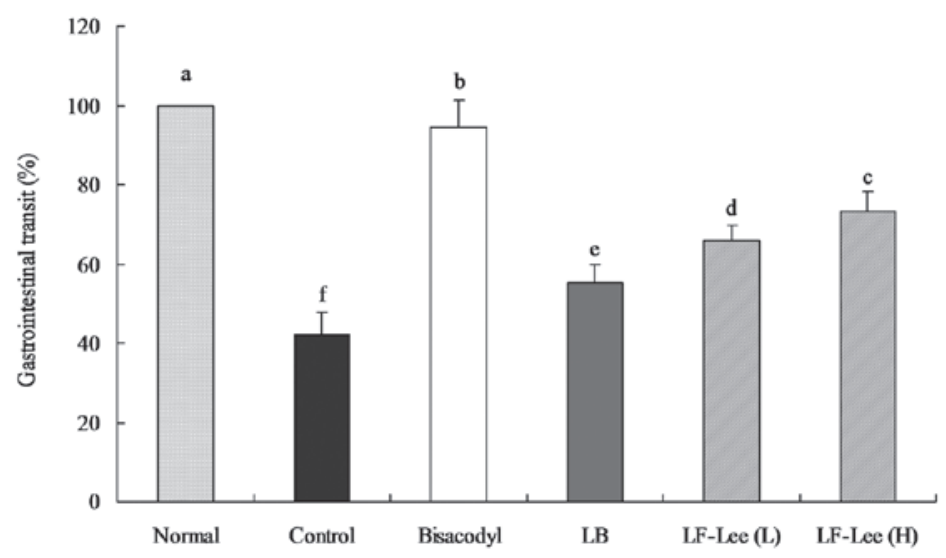

Figure 3. Effect of various treatments on the gastrointestinal (GI) transit in the mouse model of activated carbon-induced constipation (n=10 per group). The dose of bisacodyl was $100 \mathrm{mg} / \mathrm{kg}$ body weight (bw). LB, Lactobacillus bulgaricus $\left[1.0 \times 10^{9}\right.$ colony-forming unit (CFU)/kg bw]; LF-Lee (L), Lactobacillus fermentum Lee low dose $\left(0.5 \times 10^{9} \mathrm{CFU} / \mathrm{kg}\right.$ bw); LF-Lee $(\mathrm{H})$, Lactobacillus fermentum Lee high dose $\left(1.0 \times 10^{9} \mathrm{CFU} / \mathrm{kg}\right.$ bw); ${ }^{\mathrm{a}-\mathrm{f}}$ Mean values with different letters over the bars are significantly different $(\mathrm{P}<0.05)$ according to Duncan's multiple range test.

In experiments designed to imitate the environment in the stomach and guts, the tolerance of probiotics to gastric juice and cholate were investigated. The present study revealed that LF-Lee has a stronger tolerance to gastric juice and cholate than the common lactic acid bacteria LB. Thus, LF-Lee is likely to have a higher survival rate upon entering the stomach and guts, with the majority of the bacteria reaching the small intestine. Furthermore, the experiment testing the hydrophobic properties of the bacteria in the current study indicate that LF-Lee is likely to adhere more strongly than LB to the walls of the small intestine and, thus, that a greater number of LF-Lee bacteria should be able to take effect in the small intestine.

During constipation, excrement remains in the small intestine for an abnormally long period of time. Harmful bacteria may consume this excrement and proliferate, thus threatening the health of the intestines and compounding the constipation. Other organs may suffer from damage if the intestines absorb the harmful substance produced by these bacteria (20). Following constipation, the small intestine is alkaline and lactic acid bacteria produce large amounts of acid to adjust the $\mathrm{pH}$ value, thus making the environment in the intestines disadvantageous to the growth of harmful bacteria (21). Lactic acid bacteria may also promote GI tract movement and produce active material beneficial to the intestine, thereby preventing further constipation.

Compared with patients with constipation, MTL, Gas, ET, AChE, SP and VIP levels in the serum of healthy individuals are higher whilst the levels of SS are lower (22-24). MTL is a type of GI hormone. It is able to promote intestinal peristalsis and contraction of the intestinal smooth muscle, thus hastening the passing of intestinal contents through the intestinal tract. Gas is a GI hormone that is able to promote GI movement by stimulating GI secretion and stomach contraction. Furthermore, it can also promote contraction of the pyloric sphincter (22). ET is an important element that adjusts cardiovascular functions. Maintaining levels of ET not only prevents acute cardiovascular and cerebrovascular diseases induced by constipation but may also help patients with cardiovascular and cerebrovascular diseases avoid aggravation as a result of constipation (28). However, SS can stimulate the secretion of gastric acid and 
inhibit the release of pepsin and gastrin, thus aggravating constipation. The release of AChE may help promote the growth of nervous tissue, avoid enteric neuromuscular disease, which is a type of colonic pseudoobstruction, and prevent the development of constipation (28). SP is a type of excitatory neuropeptide that is able to stimulate bowel motility; reductions in the levels of SP are associated with rectal sensory dysfunction. Furthermore, rectal sensory dysfunction increases rectal compliance leading to constipation (29). VIP is a type of non-cholinergic inhibitory neuropeptide. It can influence bowel motility, as it is able to cause descending relaxation during intestinal peristaltic reflex. If the level of VIP is not sufficiently high, the level of normal enteric nerves is affected, leading to constipation (30).

The aim of the current study was to investigate whether the lactic acid bacteria LF-Lee had a preventive effect against activated carbon-induced constipation in mice. LF-Lee exhibited better qualities of acid resistance, bile tolerance and hydrophobic properties than LB. In the mice treated with LF-Lee, the results demonstrated that the time to the first black stool defecation was only marginally longer than that in mice treated with bisacodyl. The GI transit was longer than that in the control mice and was similar to that in the bisacodyl group. The levels MTL, Gas, ET, AChE, SP and VIP in the LF-Lee-treated mice were higher compared with those in the control and common LB-treated mice and the levels of SS demonstrated the opposite tendency. These results suggest that LF-Lee has a significant preventive effect on activated carbon-induced constipation in mice.

\section{Acknowledgements}

This study was supported by the National Science and Technology Program of China (no. 2012BAD13B06), the Natural Science Foundation of Chongqing Science and Technology Commission (no. cstc2013jcyjA80006) and Fundamental Research Funds for the Central Universities (no. XDJK2013B010), the Scientific and Technological Research Program of Chongqing Municipal Education Commission (no. KJ131503) and the Program for Chongqing Innovative Research Team in University (no. KJTD201325).

\section{References}

1. Wu CS, Li J, Qian Y and Suo HY: Research progress of yak milk and fermented yak milk and their nutritional value. J Dairy Sci Technol 35: 43-46, 2012 (In Chinese).

2. Wu CS, Su C, Li J, Qian Y and Suo HY: The research progress and prospect of yak yogurt lactic acid bacteria. Food Ind 33: 129-133, 2012 (In Chinese).

3. Ueki A and Otsuka M: Life style risks of Parkinson's disease: association between decreased water intake and constipation. J Neurol 251 (Suppl 7): vii18-vii23, 2004.

4. Wexner SD, Beck DE, et al: A consensus document on bowel preparation before colonoscopy: prepared by a task force from the American Society of Colon and Rectal Surgeons (ASCRS), the American Society for Gastrointestinal Endoscopy (ASGE), and the Society of American Gastrointestinal and Endoscopic Surgeons (SAGES). Gastrointest Endosc 63: 894-909, 2006.

5. Farrugia G, Miller SM, Rich A, Liu X, Maines MD, Rae JL and Szurszewski JH: Distribution of heme oxygenase and effects of exogenous carbon monoxide in canine jejunum. Am J Physio 274: G350-G358, 1998.

6. Farrugia G, Lei S, Lin X, Miller SM, et al: A major role for carbon monoxide as an endogenous hyperpolarizing factor in the gastrointestinal tract. Proc Natl Acad Sci USA 100: 8567-8570, 2003.
7. Miller SM, Reed D, Sarr MG, Farrugia G and Szurszewski JH: Haem oxygenase in enteric nervous system of human stomach and jejunum and co-localization with nitric oxide synthase. Neurogastroenterol Motil 13: 121-131, 2001

8. Xue L, Farrugia G, Miller SM, Ferris CD, Snyder SH and Szurszewski JH: Carbon monoxide and nitric oxide as coneurotransmitters in the enteric nervous system: evidence from genomic deletion of biosynthetic enzymes. Proc Natl Acad Sci USA 97: 1851-1855, 2000

9. Battish R, Cao GY, Lynn RB, Chakder S and Rattan S: Heme oxygenase-2 distribution in anorectum: colocalization with neuronal nitric oxide synthase. Am J Physiol Gastrointest Liver Physiol 278: G148-G155, 2000.

10. Xiong T, Song SH, Huang JQ, Huang Y and Xie MY: Tolerance of Lactobacillus plantarum NCU116 in stimulated digestive environments. Food Sci 32: 114-117, 2011 (In Chinese).

11. Zhao WJ, Lv JL, Ma Q and Li Y: Analysis of the surface hydrophobicity of Lactobacillus acidophilus. China Dairy Ind 39: 8-11, 2011 (In Chinese).

12. Qian Y, Zhao X and Kan J: Preventive effect of resistant starch on activated carbon-induced constipation in mice. Exp Ther Med 6: 228-232, 2013.

13. Dolk A, Brodén G, Holmström B, Johansson C and Schultzberg M: Slow transit chronic constipation (Arbuthnot Lane's disease). An immunohistochemical study of neuropeptide-containing nerves in resected specimens from the large bowel. Int J Colorectal Dis 5: 181-187, 1990 .

14. Walia R, Mahajan L and Steffen R: Recent advances in chronic constipation. Curr Opin Pediatr 21: 661-666, 2009.

15. Emmanuel AV, Tack J,QuigleyEMand Talley NJ:Pharmacological management of constipation. Neurogastroenterol Motil 21 (Suppl 2): 41-54, 2009.

16. Lubowski DZ, Chen FC, Kennedy ML and King DW: Results of colectomy for severe slow transit constipation. Dis Colon Rectum 39: 23-29, 1996.

17. Mercenier A, Pavan S and Pot B: Probiotics as biotherapeutic agents: present knowledge and future prospects. Curr Pharm Des 9: 175-191, 2003.

18. Saarela M, Mogensen G, Fondén R, Mättö J and Mattila-Sandholm T: Probiotic bacteria: safety, functional and technological properties. J Biotechnol 84: 197-215, 2000.

19. Marteau P, Minekus M, Havenaar R and Huis in't Veld JH: Survival of lactic acid bacteria in a dynamic model of the stomach and small intestine: validation and the effects of bile. J Dairy Sci 80: 1031-1037, 1997.

20. Gibson GR and Roberfroid MB: Dietary modulation of the human colonic microbiota: introducing the concept of prebiotics. J Nutr 125: 1401-1412, 1995.

21. Salminen S and Salminen E: Lactulose, lactic acid bacteria, intestinal microecology and mucosal protection. Scand J Gastroenterol Suppl 222: 45-48, 1997.

22. Sjölund K, Ekman R, Akre F and Lindner P: Motilin in chronic idiopathic constipation. Scand J Gastroenterol 21: 914-918, 1986.

23. el-Salhy $\mathrm{M}$ and Norrgård $\mathrm{O}$ : Colonic neuroendocrine peptide levels in patients with chronic idiopathic slow transit constipation. Ups J Med Sci 103: 223-230, 1998.

24. Silkoff P, Karmeli F, Goldin E, Ewenson A, Gilon C, Chorev M, et al: Effect of substance P on rat gastrointestinal transit. Digest Dis Sci 33: 74-77, 1988.

25. Feighner SD, Tan CP, McKee KK, Palyha OC, Hreniuk DL, Pong SS, et al: Receptor for motilin identified in the human gastrointestinal system. Science 284: 2184-2188, 1999.

26. Preston DM, Adrian TE, Christofides ND, Lennard-Jones JE and Bloom SR: Positive correlation between symptoms and circulating motilin, pancreatic polypeptide and gastrin concentrations in functional bowel disorders. Gut 26: 1059-1064, 1985.

27. Soudah HC, Hasler WL and Owyang C: Effect of octreotide on intestinal motility and bacterial overgrowth in scleroderma. N Engl J Med 325: 1461-1467, 1991.

28. Furchgott RF and Zawadzki JV: The obligatory role of endothelial cells in the relaxation of arterial smooth muscle by acetylcholine. Nature 288: 373-376, 1980.

29. Tzavella K, Riepl RL, Klauser AG, Voderholzer WA, Schindlbeck NE and Müller-Lissner SA: Decreased substance $\mathrm{P}$ levels in rectal biopsies from patients with slow transit constipation. Eur J Gastroen Hepatol 8: 1207-1211, 1996.

30. Milner P, Crowe R, Kamm MA, Lennard-Jones JE and Burnstock G: Vasoactive intestinal polypeptide levels in sigmoid colon in idiopathic constipation and diverticular disease. Gastroenterology 99: 666-675, 1990. 